\title{
First Detailed Anatomical Study of Bonobos Reveals Intra-Specific Variations and Exposes Just-So Stories of Human Evolution, Bipedalism, and Tool Use
}

\author{
Rui Diogo* \\ Department of Anatomy, Howard University, Washington, DC, United States
}

OPEN ACCESS

Edited by:

Sergio Balari,

Universidad Autónoma de Barcelona,

Spain

Reviewed by:

Pedro Martinez,

Universitat de Barcelona, Spain

Frietson Galis,

Naturalis Biodiversity Center,

Netherlands

Laura Nuño De La Rosa,

KLI Institute, Austria

*Correspondence:

Rui Diogo

rui.diogo@howard.edu

Specialty section:

This article was submitted to

Evolutionary Developmental Biology,

a section of the journa

Frontiers in Ecology and Evolution

Received: 11 February 2018

Accepted: 11 April 2018

Published: 26 April 2018

Citation:

Diogo R (2018) First Detailed Anatomical Study of Bonobos Reveals Intra-Specific Variations and Exposes Just-So Stories of Human Evolution,

Bipedalism, and Tool Use.

Front. Ecol. Evol. 6:53.

doi: $10.3389 /$ fevo.2018.00053
Just-so stories are prominent in human evolution literature because of our tendency to create simple progressionist narratives about our "special" place in nature, despite the fact that these stories are almost exclusively based on hard tissue data. How can we be so certain about the evolution of human facial communication, bipedalism, tool use, or speech without detailed knowledge of the internal anatomy of for instance, one of the two extant species more closely related to us, the bonobos? Here I show how many of these stories now become obsolete, after such a comprehensive knowledge on the anatomy of bonobos and other primates is finally put together. Each and every muscle that has been long accepted to be "uniquely human" and to provide "crucial singular functional adaptations" for our bipedalism, tool use and/or vocal/facial communication, is actually present as an intra-specific variant or even as normal phenotype in bonobos and/or other apes.

Keywords: chimpanzees, apes, bonobos, biological anthropology, functional morphology, muscles, human evolution

Just-so stories (Smith, 2016) are frequent in the literature about human evolution because of our tendency to build simple progressionist narratives about our "special" evolutionary history and place in nature (Gould, 1993, 2002). This is particularly striking because these stories are in reality almost exclusively based on hard tissue data. In fact, descriptions of the soft tissues of apes have been relatively scarce and mainly referred to just a few muscles of the head or limbs of a single taxon, in most cases (e.g., Tyson, 1699; Bischoff, 1880; Raven, 1950; Swindler and Wood, 1973; Diogo and Wood, 2011, 2012; Persaud and Loukas, 2014). For instance, the only study that specifically focused on the musculature of bonobos (Pan paniscus) was that of Miller (1952), which was based on dissections of a single adult and did not provide information for numerous head and limb muscles (Diogo and Wood, 2011, 2012). Strikingly, despite this scarcity of information, biologists and anthropologists have displayed a remarkable confidence in their stories about the origin and evolution of human soft tissues, including their phylogenetic distribution and "singular functional adaptations."

To illustrate this fact, in this short paper I will refer here briefly to seven muscles that have long been generally seen as "unique human features" and linked with specific adaptations for our bipedalism, tool use, and vocal or facial communication. Firstly, the facial expression muscle risorius (Figure 1) has been generally accepted as a unique feature crucial for the evolution of our 


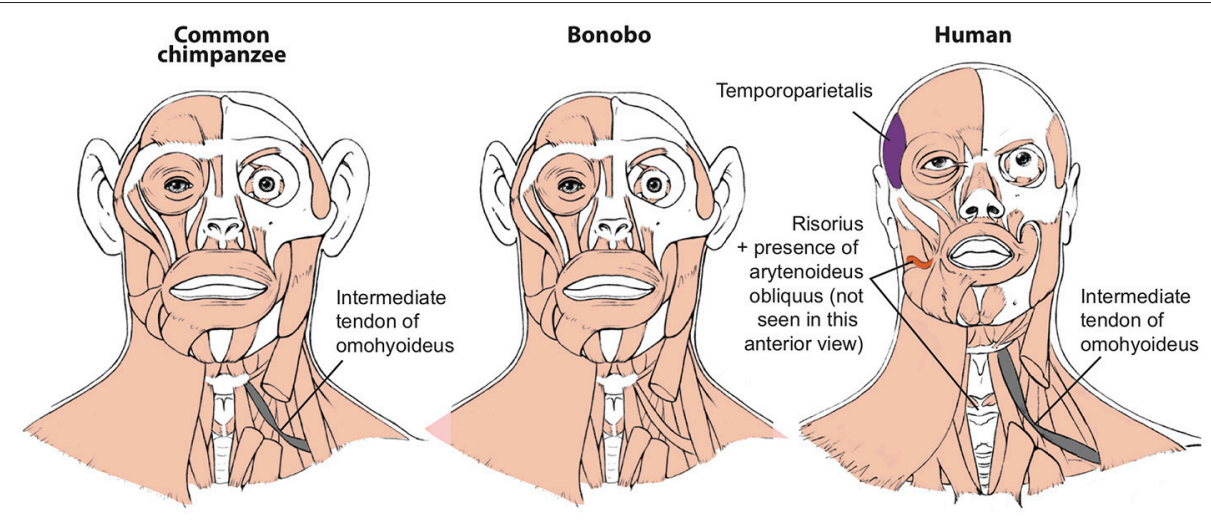

FIGURE 1 | Differences between head muscles of common chimps, bonobos, and humans, based and modified from Diogo et al. (2017b). There are no major consistent differences concerning the presence/absence of muscles in adult common chimps (left) and bonobos (center), the only minor difference (shown in gray in the common chimp scheme) being that the omohyoideus has no intermediate tendon in bonobos, contrary to common chimps (and humans). In contrast, there are many differences between bonobos and humans (right) concerning the presence/absence of muscles in the normal phenotype (shown in colors and/or with labels in the human scheme). Modified from Diogo et al. (2017b); (c) Diogo has copyright of these figures.

"gracile" smile and "specially sophisticated" facial communication abilities (Huber, 1931). In a very influential paper, Susman et al. argued-although (fortunately) not as confidently as the assertions done by some of the other authors cited here-that the hand muscle adductor pollicis accessorius (Figure 2; "Henle" or "interosseous volaris primus" muscle: Bello-Hellegouarch et al., 2013) is a unique feature likely related to our increased ability to manufacture and/or use tools (Susman et al., 1999). Similarly, the foot muscle adductor hallucis accessorius - which topologically corresponds to the adductor pollicis accessorius of the hand-is also often considered to be uniquely found in our bipedal species, being at least consistently present at early stages of our ontogenetic development (Cihak, 1972). The foot muscle fibularis tertius (Figure 3) is, according to Lewis' (1989) highly influential monograph on the evolution of our limbs, a unique feature most likely associated with our bipedal evolution (Lewis, 1989). The flexor pollicis longus and extensor pollicis brevis (Figure 2) are forearm muscles that insert onto the thumb and that are generally considered to be unique adaptations for human tool manufacture and use (Lewis, 1989). For instance, it has been experimentally shown that the recruitment to these two muscles allows human subjects to maintain the metacarpophalangeal joint in extension while flexing the distal phalanx of the thumb, i.e., two primary movements usually done when we grab/manipulate objects (Marzke et al., 1998; Williams et al., 2012). Lastly, the laryngeal muscle arytenoideus obliquus has long been considered to be a unique feature of humans-which also have an arytenoideus transversus, in contrast to the single arytenoideus muscle said to occur in all other primates-associated to our enhanced vocal communication (reviewed in Diogo and Wood, 2012).

In the last years, my colleagues and I compiled the scarce information available in the literature on primate muscles and compared it to the results obtained from our dissections of representatives of all major primate groups, in order to test assertions and accepted ideas such as those mentioned in the above paragraph (Diogo et al., 2010, 2012, 2013a,b, 2014; Diogo and Wood, 2011, 2012). This goal can now be undertaken because recently my colleagues and I were able to study in detail the internal anatomy of a total of seven-six fresh (frozen) and one embalmed (formalin)-bonobo specimens that died from natural causes. This has been one of the most challenging and enduring quests faced by biological anthropologists, due to the very scarce number of bonobo specimens available in Western museums and zoos (Diogo and Wood, 2012). We published our detailed observations in an anatomical atlas of bonobos, which provides notes about variations as well as comparisons with humans, common chimpanzees, and other primates (Diogo et al., 2017b). As that atlas did not discuss the broader evolutionary implications of the obtained comparative data, the aim of the present short paper is to provide a discussion of those broader implications. The short summary provided below exposes major flaws on each and every of the commonly accepted "stories" about how the seven muscles listed above are "uniquely found" in humans and were "specially important adaptations" within our evolutionary history. This is because, contrarily to the ideas used in such "stories", each of these muscles is actually present as a variant or even as the normal phenotype of at least one group of our living closer relatives, the apes.

The fibularis tertius, commonly associated with human bipedalism (e.g., Lewis, 1989, see above), was present in almost half $(3 / 7)$ of the dissected bonobos (in the fetus, infant Etje, and adolescent Jasiri), going to metatarsal V-exactly as it normally does in humans-in the fetus and infant, and to the proximal phalanx of digit 5 in the adolescent (see, e.g., Figure 4A). As bonobos are obviously not fully bipeds (in fact, even their peculiar type of "bipedal walking" has been recorded as $<1 \%$ of terrestrial locomotion in the wild: e.g., Doran, 1993), stating that the presence of this muscle is necessarily related to, and brought adaptative advantages for, human bipedalism (e.g., Lewis, 1989) does seem to be mainly an unsupported just-so-story. Similarly, the adductor pollicis accessorius, or "Henle" muscle of the hand, 

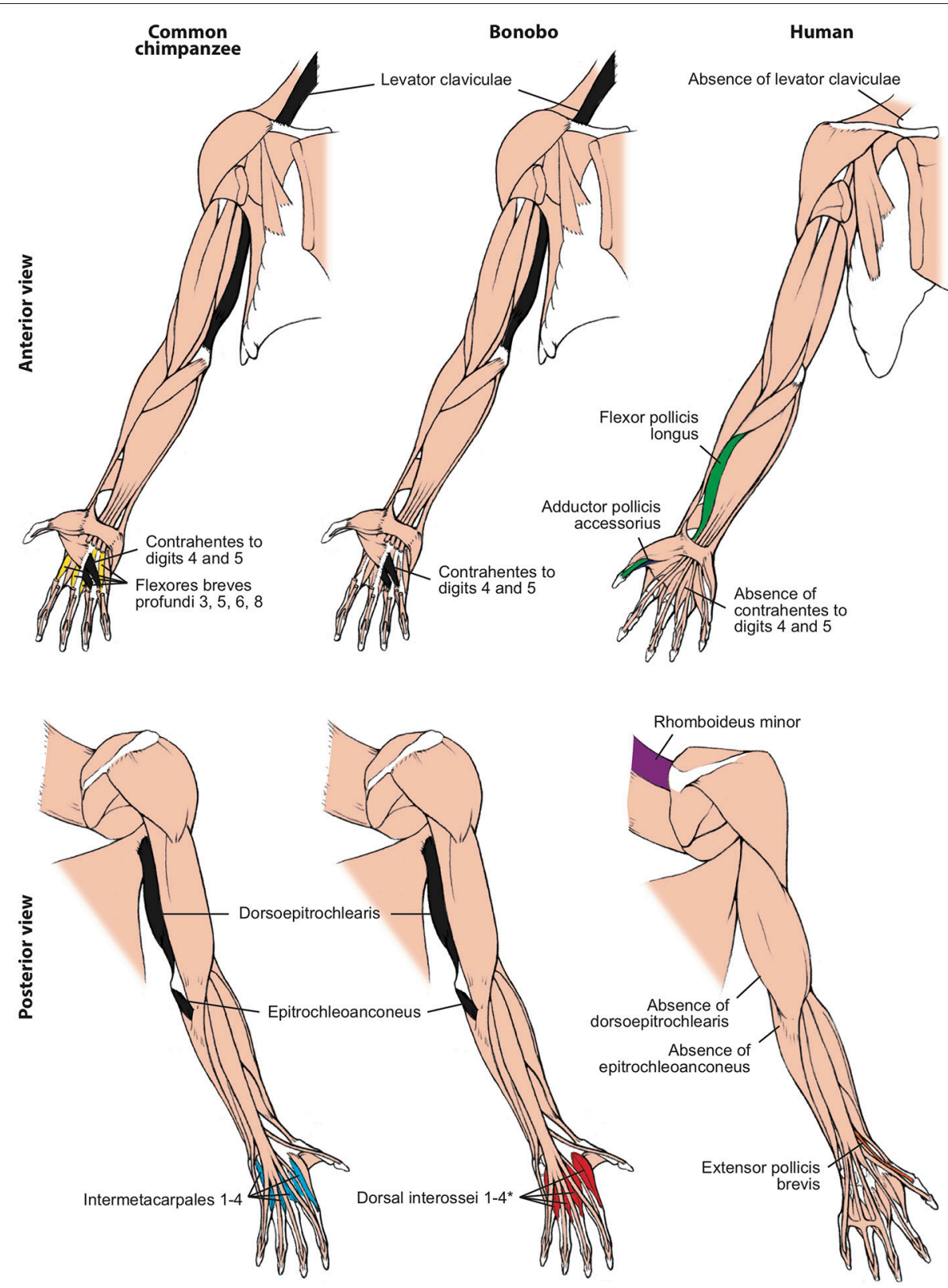

FIGURE 2 | Differences between forelimb muscles of common chimps, bonobos and humans, based and modified from Diogo et al. (2017b). The only consistent difference between bonobos (center) and common chimps (left) concerning the presence/absence of muscles (shown in colors in the common chimps and bonobos schemes) is that in the former the intermetacarpales $1-4$ are usually fused with the flexores breves profundi $3,5,6$, and 8 to form the dorsal interossei muscles $1-4$ ( ${ }^{*}$ in bonobo) figure, as is the case in humans. In contrast, there are many differences between bonobos and humans (right) concerning the presence/absence of muscles (shown in colors and/or with labels in the human scheme; muscles present in chimps and not in humans are shown in black, in chimps). Modified from Diogo et al. (2017b); @ Diogo has copyright of these figures.

said to be linked to our enhanced ability to manufacture and use tools (e.g., Susman et al., 1999), was present in two (fetus and infant Etje) of the seven dissected bonobos, running mainly from metacarpal I to the thumb's proximal phalanx, as it often does in humans (see, e.g., Figure 4B). Moreover, our comparisons indicate that this muscle corresponds to a muscle described in the past by a few other authors and also found by us in common chimpanzees ( $P$. troglodytes) as well as in gorillas (Diogo et al.,
2010, 2013b). Furthermore, the adductor hallucis accessorius, i.e., the "Henle" muscle of the foot, which had never been described in non-human primates in the past, was also present in three (fetus, infant Etje, and adolescent Jasiri) bonobos dissected by us (see, e.g., Figure 5A), and in an adult $P$. troglodytes specimen that we dissected together with the bonobos for that bonobo atlas.

Another assumption that is taken for granted is that our hand/forearm structures are highly derived, when compared to 


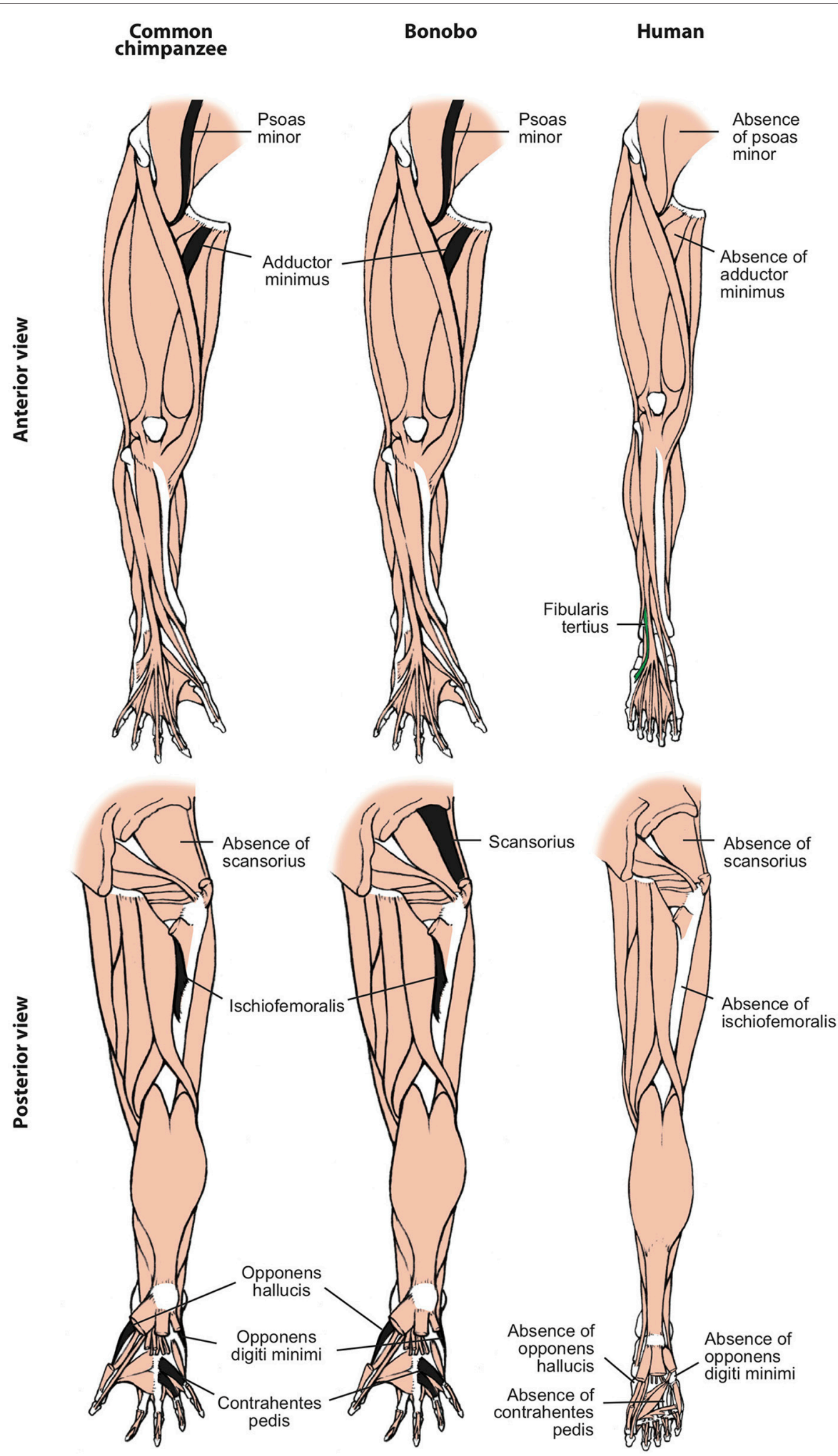

FIGURE 3 | Differences between hindlimb muscles of common chimps, bonobos and humans, based and modified from Diogo et al. (2017b). The only consistent difference between bonobos (center) and common chimps (left) concerning the presence/absence of muscles (shown in colors in the common chimps scheme) is that the latter usually lack the scansorius, as is the case in humans. In contrast, there are many differences between bonobos and humans (right) concerning the presence/absence of muscles (shown in colors and/or with labels in the human scheme; muscles present in chimps and not in humans are shown in black, in chimps). Modified from Diogo et al. (2017b); (c) Diogo has copyright of these figures. 

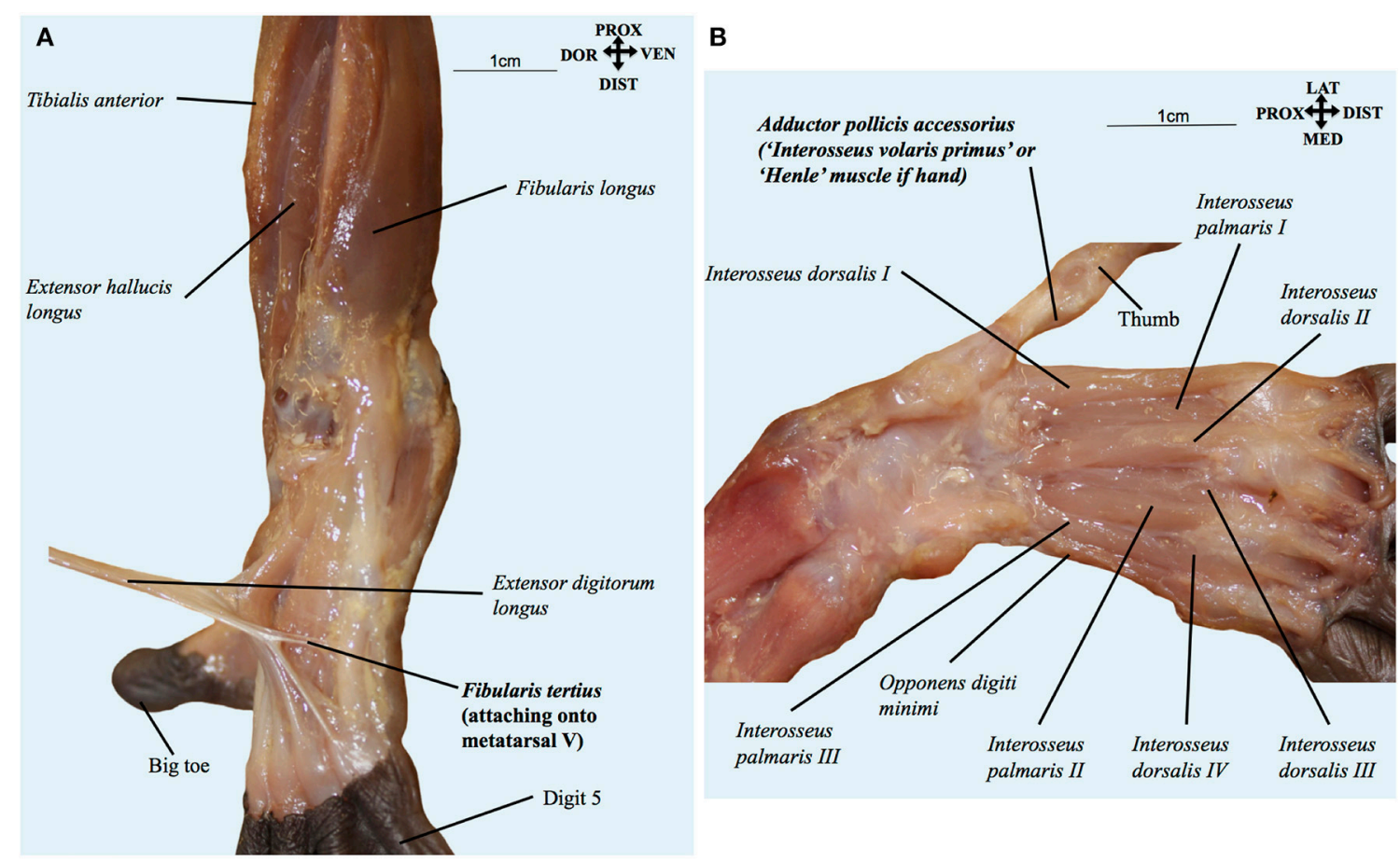

FIGURE 4 | (A) Pan paniscus (ZIMS 164052, Ano, fetus female): dorsolateral view of the superficial muscles of the left foot. Extensor digitorum longus is detached showing the fibularis tertius tendon going to the fifth metatarsal. Modified from Diogo et al.'s photographic atlas of bonobos Diogo et al. (2017a); (c) Diogo has copyright of this atlas. (B) Pan paniscus (ZIMS 164052, Ano, fetus female): ventral view of the deep muscles of the hand after removal of contrahentes; note the presence of the adductor pollicis accessorius ("interosseus volaris primus or Henle's muscle”). Modified from Diogo et al.'s photographic atlas of bonobos Diogo et al. (2017a); ( ) Diogo has copyright of this atlas.

those of great apes (e.g., Susman et al., 1999; Young, 2003). Within this assumption, the occurrence of a vestigial/absent tendon of the flexor digitorum profundus to digit 1 often seen in orangutans, gorillas, and common chimpanzees is contrasted to the supposedly derived condition found in humans in which the tendon is not only stout but forms a distinct muscle flexor pollicis longus. As noted above, this muscle and the extensor pollicis brevis are generally seen as crucial adaptations to our peculiar tool manufacture/use abilities. However, our study of bonobos revealed that, contrary to common chimpanzees and other great apes, the tendon of the flexor digitorum profundus to digit 1 is actually always a stout, non-vestigial structure (in all seven bonobos dissected by us; see, e.g., Figure 5B), as is the case with the corresponding tendon of the flexor pollicis longus in humans. Therefore, it is equally parsimonious to assume that the tendon became vestigial independently in orangutans, gorillas and common chimpanzees (three steps) or became vestigial in the clade including great apes and humans, and then stout again in humans and bonobos (three steps). In fact the former hypothesis is in line with a recent study including fossils that put in question the supposedly derived configuration of the humans hand because it indicates that the proportions of our hand are likely more ancestral than previously thought (Almécija et al., 2015), as well as with the fact that hylobatids and most non-ape primates have a stout tendon (Diogo and Wood, 2012).
In fact, our recent dissections and comparisons revealed that in hylobatids-which are the living sister-group of the great-ape + human clade-the tendon is not only stout but, strikingly, is also part of a distinct flexor pollicis longus muscle, exactly as seen in humans (Diogo et al., 2012). Furthermore, hylobatids also have a distinct extensor pollicis brevis, which according to ideas that were taken for granted was supposedly only found in humans and also an adaptation for human tool manufacture/use (see review by Diogo et al., 2012). There are increasing reports on the occurrence of tool use and even manufacture in apes, but so far there is no indication that hylobatids are in any way particularly "sophisticated" in this sense (Shea, 2017). Therefore, the accepted idea that there is a necessary link between the presence of these two muscles and an enhanced tool use/manufacture ability (e.g., Marzke et al., 1998; Susman et al., 1999) becomes, now, another example of a just-so-story. Similarly, our recent dissections and comparisons revealed that the laryngeal muscle arytenoideus obliquus, for long seen as a unique human feature likely related to the evolution of our speech, is found in a few common chimpanzees (not in bonobos, so far) and various gorillas (Diogo et al., 2010, 2013b). Lastly, the risorius, the supposed landmark of our "uniquely sophisticated facial expression," was also found in various common chimpanzees (not in bonobos, so far) and various gorillas (Diogo et al., 2010, 2013b). 


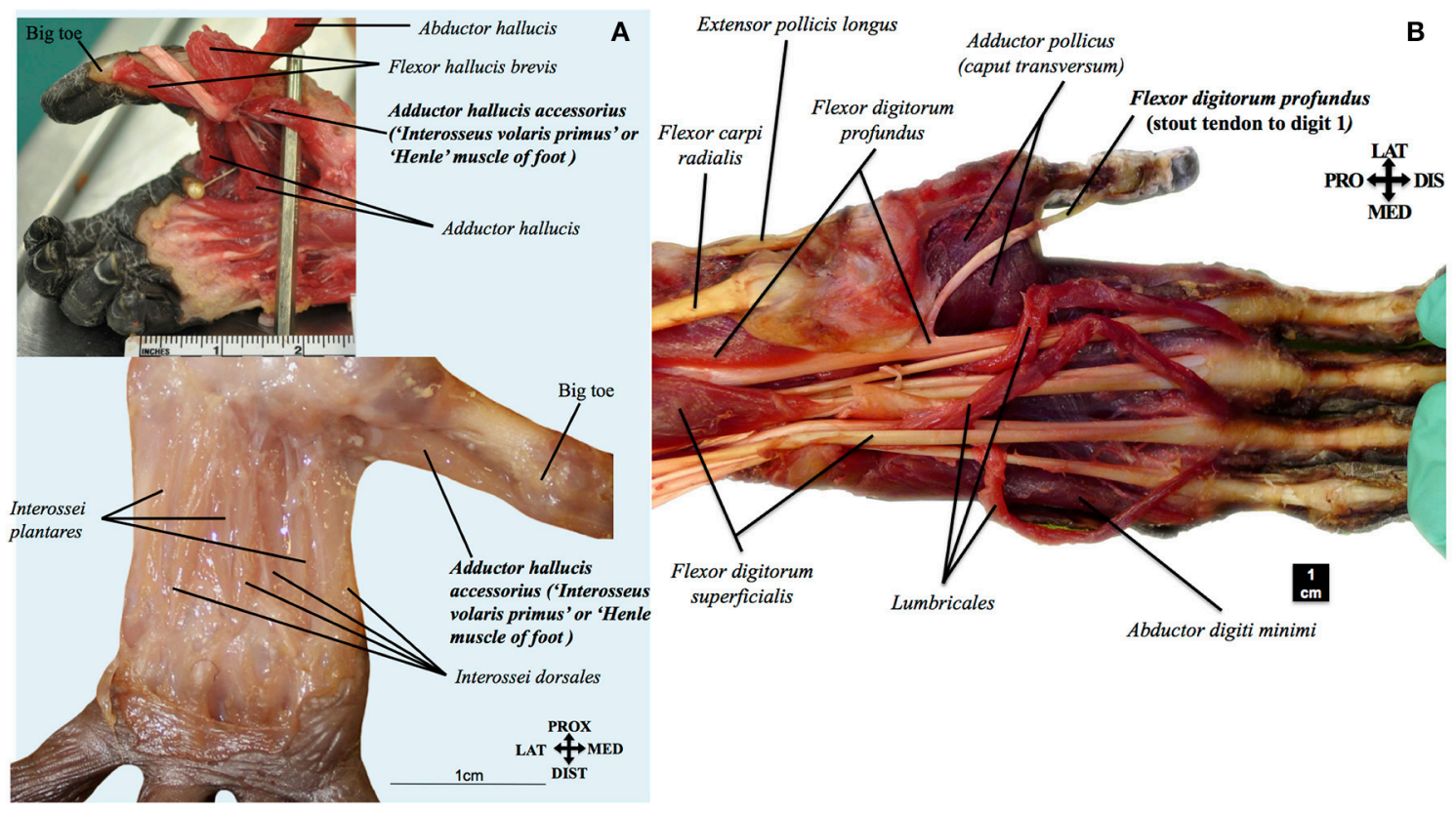

FIGURE 5 | (A) Pan paniscus: top ZIMS 164047, Jasiri, adolescent female; bottom ZIMS 164052, Ano, fetus female. Plantar view of the deep muscles of the foot, showing the presence of adductor hallucis accessorius (interosseous volaris primus of Henle). Modified from Diogo et al.'s photographic atlas of bonobos Diogo et al. (2017a); ( ) Diogo has copyright of this atlas. (B) Pan paniscus (ZIMS 164031, Kidogo, adult male): palmar view of the superficial muscles of the left hand, showing that the tendon of the flexor digitorum profundus to digit 1 is a stout, non-vestigial structure in bonobos, contrary to common the configuration often seen in common chimpanzees, gorillas, and orangutans. Modified from Diogo et al.'s photographic atlas of bonobos Diogo et al. (2017a); @ Diogo has copyright of this atlas.

Therefore, the detailed study of the internal anatomy of our closest relatives, the apes, exposes the fallacy of the simplistic and progressivist narratives that have been accepted for so long-and continue to be-, often as dogmas. Only the strong bias toward a vision of humans as so special and specialized, associated with a clearly outdated extreme adaptationist framework (see Diogo, 2017), can explain how those ideas became to be so easily accepted, without being tested against actual empirical data about the internal anatomy of other primates. The picture that now emerges is clearly more complex and less progressionist, including the occurrence of a high level of intraspecific variation within all major extant ape groups. Accordingly, this new scenario requires a more thorough examination of why these muscles are present in apes, and in particular in just a subset of the normal population within a certain species such as bonobos. Are these muscles somewhat useful for the individuals having them, as adaptationists would argue, or are they just evolutionary neutral and related to the occurrence of developmental constraints and/or simply the byproducts of other features (e.g., Gould, 2002)? Within this latter context, could it be that humans simply evolved from a subset of a population that happen to have those features as variants, i.e., that their presence in our ancestors was mainly due to factors such as drift/randomness, at least during the earlier stages of our evolutionary history? What we need is therefore to re-examine the evolution of human soft tissues and their functional morphology in a less prejudiced way, replacing ad hoc just-so-stories with an empiricist mind-set.

\section{AUTHOR CONTRIBUTIONS}

The author confirms being the sole contributor of this work and approved it for publication.

\section{ACKNOWLEDGMENTS}

I would like to thank the team of researchers that paved the way for and, or contributed to the dissections of the bonobos that I lead at the Antwerp University in Belgium, as well as all the other people that were previously involved in the dissections and scanning of common chimpanzees, gorillas, orangutans, hylobatids, and other primate and non-primate mammals. Among these researchers I want to thank in particular to Sandra Nauwelaerts (Univ. Antwerp, Belgium) for making the bonobo dissections possible, Francisco Pastor (Univ. Valladolid, Spain) for providing most of the other ape specimens that we studied during these years, and Bernard Wood for being first my advisor and then my closer colleague during all these years of study of primate internal anatomy. This project has received funding from NSF grants 1516557 and 1440624 to RD. 


\section{REFERENCES}

Almécija, S., Smaers, J. B., and Jungers, W. L. (2015). The evolution of human and ape hand proportions. Nat. Commun. 6:7717. doi: 10.1038/ncomms8717

Bello-Hellegouarch, G., Aziz, M. A., Ferrero, E. M., Kern, M., Francis, N., and Diogo, R. (2013). "Pollical palmar interosseous muscle" (musculus adductor pollicis accessorius): attachments, innervation, variations, phylogeny, and implications for human evolution and medicine. J. Morphol. 274, 275-293. doi: 10.1002/jmor.20090

Bischoff, T. L. W. (1880). Beitrage zur anatomie des gorilla. Abh. Bayer. Akad. Wiss. Munchen Math. Phys. Kl. 13, 1-48.

Cihak, R. (1972). Ontogenesis of the skeleton and intrinsic muscles of the human hand and foot. Adv. Anat. Embryol. Cell Biol. 46, 1-194.

Diogo, R. (2017). Evolution Driven by Organismal Behavior: A Unifying View of Life, Function, Form, Mismatches and Trends. New York, NY: Springer.

Diogo, R., Molnar, J., and Wood, B. (2017a). Bonobo anatomy reveals stasis and mosaicism in chimpanzee evolution, and supports bonobos as the most appropriate extant model for the common ancestor of chimpanzees and humans. Nat. Sci. Rep. 7:608. doi: 10.1038/s41598-017-00548-3

Diogo, R., Pastor, J. F., Hartstone-Rose, A., and Muchlinski, M. N. (2014). Baby Gorilla: Photographic and Descriptive Musculoskeletal Atlas of The Skeleton, Muscles and Internal Organs - Including CT Scans and Comparisons to Other Gorillas and Primates. Oxford: Taylor \& Francis.

Diogo, R., Potau, J. M., Pastor, J. F., de Paz, F. J., Arias-Martorell, J., Turcotte, C., et al. (2017b). Photographic and Descriptive Musculoskeletal Atlas of Bonobos, with Notes on the Attachments, Variations, Innervation, Synonymy and Weight of the Muscles. New York, NY: Springer.

Diogo, R., Potau, J. M., Pastor, J. F., de Paz, F. J., Ferrero, E. M., Bello, G., et al. (2010). Photographic and Descriptive Musculoskeletal Atlas of Gorilla - with Notes on the Attachments, Variations, Innervation, Synonymy and Weight of the Muscles. Oxford: Taylor \& Francis.

Diogo, R., Potau, J. M., Pastor, J. F., de Paz, F. J., Ferrero, E. M., Bello, G., et al. (2012). Photographic and Descriptive Musculoskeletal Atlas of Gibbons and Siamangs (Hylobates) - with Notes on the Attachments, Variations, Innervation, Synonymy and Weight of the Muscles. Oxford: Taylor \& Francis.

Diogo, R., Potau, J. M., Pastor, J. F., de Paz, F. J., Ferrero, E. M., Bello, G., et al. (2013a). Photographic and Descriptive Musculoskeletal Atlas of Orangutans (Pongo) - with Notes on the Attachments, Variations, Innervation, Synonymy and Weight of the Muscles. Oxford: Taylor \& Francis.

Diogo, R., Potau, J. M., Pastor, J. F., de Paz, F. J., Ferrero, E. M., Bello, G., et al. (2013b). Photographic and Descriptive Musculoskeletal Atlas of Chimpanzees (Pan) - with Notes on the Attachments, Variations, Innervation, Synonymy and Weight of the Muscles. Oxford: Taylor \& Francis.

Diogo, R., and Wood, B. (2011). Soft-tissue anatomy of the primates: phylogenetic analyses based on the muscles of the head, neck, pectoral region and upper limb, with notes on the evolution of these muscles. J. Anat. 219, 273-359. doi: 10.1111/j.1469-7580.2011.01403.x
Diogo, R., and Wood, B. (2012). Comparative Anatomy and Phylogeny of Primate Muscles and Human Evolution. Oxford: Taylor and Francis.

Doran, D. M. (1993). Comparative locomotor behavior of chimpanzees and bonobos: the influence of morphology on locomotion. Am. J. Phys. Anthropol. 91, 83-98.

Gould, S. J. (1993). Cordelia's dilemma. Nat. Hist. 102, 10-18.

Gould, S. J. (2002). The Structure of Evolutionary Theory. Harvard: Belknap.

Huber, E. (1931). Evolution of Facial Musculature and Expression. Baltimore, MD: The Johns Hopkins University Press.

Lewis, O. J. (1989). Functional Morphology of the Evolving Hand and Foot. Oxford: Clarendon Press.

Marzke, M. W., Toth, N., Schick, K., Reece, S., Steinberg, B., Hunt, K., et al. (1998). EMG study of hand muscle recruitment during hard hammer percussion manufacture of Oldowan tools. Am. J. Phys. Anthropol. 105, $315-332$.

Miller, R. A. (1952). The musculature of Pan paniscus. Am. J. Anat. 91, 182-232.

Persaud, T. V. N., and Loukas, M. (2014). A History of Human Anatomy, 2nd Edn. Springfield, IL: Charles C Thomas.

Raven, H. C. (1950). "Regional anatomy of the gorilla," in The Anatomy of the Gorilla, ed W. K. Gregory (New York, NY: Columbia University Press), 15-188.

Shea, J. J. (2017). Stone Tools in Human Evolution - Behavioral Differences among Technological Primates. Cambridge: Cambridge University Press.

Smith, R. J. (2016). Freud and evolutionary anthropology's first just-so story. Evol. Anthropol. 25, 50-53. doi: 10.1002/evan.21476

Susman, R. L., Nyati, L., and Jassal, M. S. (1999). Observations on the pollical palmar interosseus muscle (of Henle). Anat. Rec. 254, 159-165.

Swindler, D. R., and Wood, C. D. (1973). An Atlas of Primate Gross Anatomy: Baboon, Chimpanzee and Men. Seattle, WA: University of Washington Press.

Tyson, E. (1699). Orang-Outang sive Homo Sylvestris, or the Anatomy of a Pygmie Compared to That of a Monkey, an Ape and a Man. London: T. Bennet.

Williams, E. M., Gordon, A. D., and Richmond, B. G. (2012). Hand pressure distribution during Oldowan stone tool production. J. Hum. Evol. 62, 520-532. doi: 10.1016/j.jhevol.2012.02.005

Young, R. W. (2003). Evolution of the human hand: the role of throwing and clubbing. J. Anat. 202, 165-174. doi: 10.1046/j.1469-7580.2003. 00144.x

Conflict of Interest Statement: The author declares that the research was conducted in the absence of any commercial or financial relationships that could be construed as a potential conflict of interest.

Copyright (c) 2018 Diogo. This is an open-access article distributed under the terms of the Creative Commons Attribution License (CC BY). The use, distribution or reproduction in other forums is permitted, provided the original author(s) and the copyright owner are credited and that the original publication in this journal is cited, in accordance with accepted academic practice. No use, distribution or reproduction is permitted which does not comply with these terms. 